\title{
Jordanian Cloud-Government between Implementation and Challenges
}

\author{
Wafa' Slaibi Alsharafat \\ Prince Hussein Bin Abdullah \\ College for Information \\ Technology \\ AL al-Bayt University \\ Mafraq, Jordan
}

\author{
Bader M. AlFawwaz \\ Prince Hussein Bin Abdullah \\ College for Information \\ Technology \\ AL al-Bayt University \\ Mafraq, Jordan
}

\author{
Atallah M. AL-Shatnawi \\ Prince Hussein Bin Abdullah \\ College for Information \\ Technology \\ AL al-Bayt University \\ Mafraq, Jordan
}

\begin{abstract}
Cloud computing is a modern style of advance and modernization in network environment which takes the advantage of a various wire and wirelss technologies as distributed, and parallel processing which oriented to service architecture. The E-government services are concerned about sharing existing resources. E-governments are available online and they have to adapt new technology that will enhance the service provided to their citizens. This paper focuses on cloud computing and e-government concepts and identifies the ways for implementing cloud computing in Jordanian e-government through a set of stages regarding the main challenges for this adaptation
\end{abstract}

\section{Keywords}

E-government, Cloud environment.

\section{INTRODUCTION}

Many countries around the world have adopted new technology and innovation concepts to transform public service to their citizens efficiently and effectively. As for developing countries, they have started to adopt new technology to develop their strategic plans to enable citizen, business enterprises and governmental agencies to interchange information and high quality services. To reach these expectations, government moves from old-style government services to modern and up-to-date E-government services, using different ways such as webpages, social networks, and wireless communications. Also enable citizens to admin their own procedures electronically through government agencies.

E-government activities can be categorized into different classes [1] but all classes have shared goals concerned about improving efficiency, reliability, quality of services and rise their citizen's life style standards.

\section{E-government categorized into:}

1- Government-to-government (G 2 G): which aims to reduce cost by speeding up the transaction, reducing number of government employees to produce steady and uniform outcomes? Also, G2G concerns about sharing and exchanging data electronically between multi governmental agencies.

2- Government-to- citizens (G 2 C): enable citizens to interact and conduct their transaction directly with government agencies through government portals which acts as a single access point between citizens with multi government agencies. These transactions include taxes, Electronic Benefits Transfer (EFT) etc.

3- Government to business (G 2 B): this class enables collaboration between government and business enterprises to carry out their own activities such as sales, procurement etc.

However, many governments, as Jordanian E-government, are trapped in the first stages of E-government services implementing. Hashemite Kingdom of Jordan witnesses improvement in Information technology and telecommunication and this shown by Jordanian egovernment rank compared with other countries.

Jordanian e--government stated in rank 8 between 16 countries as shown in table 1 [2].

Table 1. Some countries rank in terms of e-government [2].

\begin{tabular}{|c|c|}
\hline Country Name & E-Government Rank \\
\hline Bahrain & 18 \\
\hline United Arab Emirates & 32 \\
\hline Saudi Arabia & 36 \\
\hline Qatar & 44 \\
\hline Oman & 48 \\
\hline Kuwait & 49 \\
\hline Tunisia & 75 \\
\hline Jordan & 79 \\
\hline Egypt & 80 \\
\hline Morocco & 82 \\
\hline Lebanon & 89 \\
\hline Libya & 121 \\
\hline Iraq & 134 \\
\hline Syrian Arab Republic & 135 \\
\hline Algeria & 136 \\
\hline Yemen & 150 \\
\hline
\end{tabular}

\section{CLOUD COMPUTING}

Cloud Computing is a new paradigm that combines different approaches as distributed systems, network communication and infrastructure. Cloud computing can be defined according to the US National Institute of Standard and Technology of (NIST) as used by the researchers in [3]: " Cloud computing is a model for enabling convenient, on-demand network access to a shared pool of configurable computing resources (e.g., networks, servers, storage, applications, and services as in 
figure 1) that can be rapidly provisioned and released with minimal management effort or service provider interaction.". Even more, researchers as in [30] adopted the IEEE Computer Society definition for Cloud Computing as: "A paradigm in which information is permanently stored in servers on the Internet and cached temporarily on clients that include desktops, entertainment centers, table computers, notebooks, wall computers, handhelds, etc."[30]

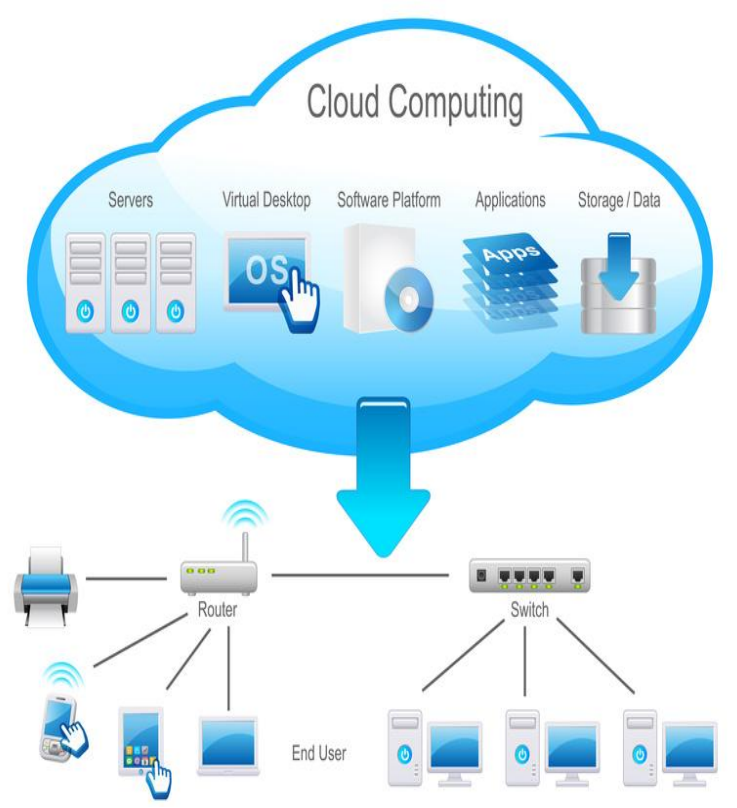

Fig. 1. Cloud Computing 1[29]

Delivering services in cloud environment can be classified into three main types; Infrastructure as a Service (IaaS), Software as a Service (SaaS) and Platform as a Service (PaaS) $[3,4]$.

In IaaS, this layer of service provides citizen with capabilities to use network and hardware to run different applications and operating systems. These capabilities include using shared storage and network resources. Even though, user not responsible for controlling these infrastructure where citizens in this case can be classified as a Thin client where operations executed remotely on cloud servers and citizen gain output results. The main goal for this layer is providing an elastic, standard, and virtual operational environment as a foundation for PaaS and SaaS.

In PaaS, this layer concerned about giving citizens the capabilities for creating, developing and testing application. A Citizen can use different programming tools compatible with the existing cloud platform. Platform risks are shared between citizens and cloud service provider because these two parts are responsible for the platform stability and architectural compliance.

In SaaS, clouds software handled as installation and execution environment for citizen's applications and programs. In addition, cloud environment is a cloud- based applications are hosted and offered as services. Furthermore, SaaS transfers operational risks from citizen part to cloud service provider. Figure $2 \& 3$ summarizes main service for each model, layer. [5].

Furthermore, SaaS, PaaS and IaaS can be classified as anything as Service (XaaS) where "X" refers to anything.
A set of research paper agreed that cloud computing has five main features $[3,6,7]$ which they are:

1. Scalability and enhanced performance: Cloud environment can increase their tendency to handle increased load on cloud resources so this environment can scale up or down depending on per user requirement. In addition, performance can be increased by adding new

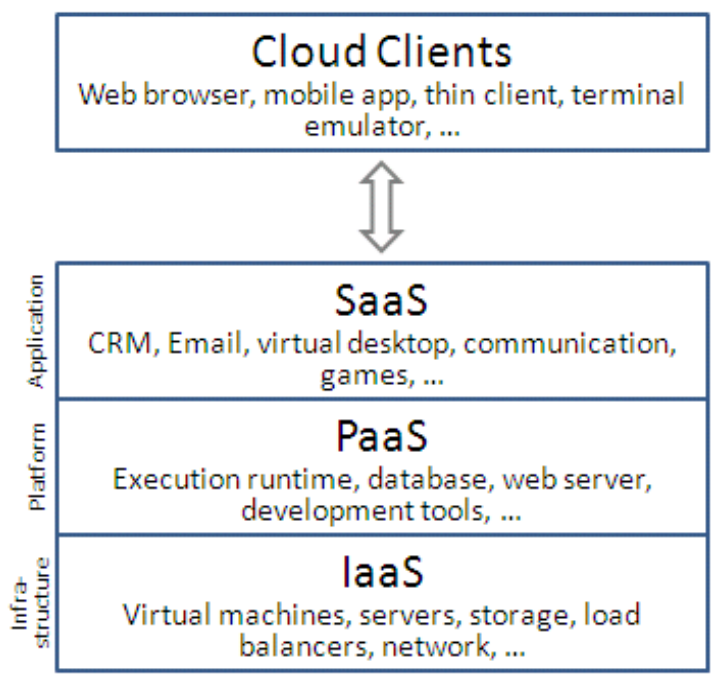

Fig. 2. Cloud computing service types[29]

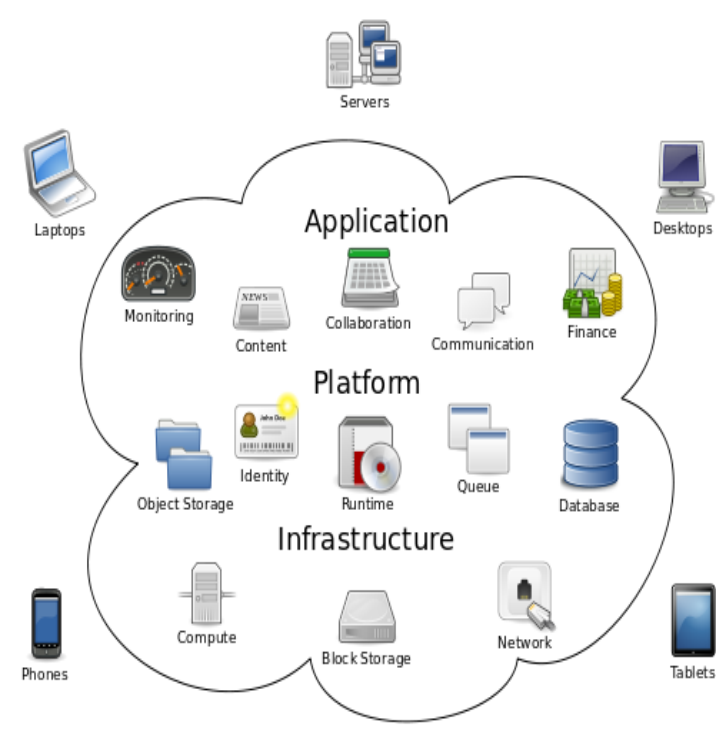

Fig. 3. Cloud Computing layers.[29]

resources to this environment.

2. Ubiquitous network access: Citizens can access to standard internet-based services by supporting thick and thin citizens as Laptops, mobile phones etc.

3. Resources Location Transparency: Citizens can access to cloud services regardless their location and time with no specific resource assigned to any citizen.

4. Rapid Elasticity: This feature concerned about keeping services updated and improved their capabilities taking into consideration changed needs of citizens.

5. Pay per use: citizens are paid fees based on their usage cloud resources e.g. bandwidth usage. 


\section{RELATED WORK}

In recent years, e-governments have changed their ways for delivering and organizing their services. E- into two dimensions; practical and technical [8]. E-government has witnessed a set of developments to make relevant service, especially online, available to citizens. The needs of citizens from e-governments have become the crucial point that guides researches and practices.

Population, citizen and segmentation with different preference structures force e-governments to deployment their transactional services to meet their expectations [9]. To accomplish these needs and expectations, there is a need to realize the diversity among citizens. Internet usage by citizens is one of main and significant challenges that face Egovernment [10, 11]. Applying e-government and related services are harder and challengeable for developing countries than developed countries [12].

E-government provides modern and up-to-date technological infrastructure for both citizens and governments agencies that have different responsiveness [13]. Rogers in [14] explained diffusion as spreading of technology throughout government agencies. For testing, e-government applications and their adaptation have been examined taking into account demographic distribution of citizens [15]. Also, government agencies seek to gain and exceed citizen's satisfaction by understanding their needs and applications [16].

\section{THE BENEFITS OF CLOUD- GOVERNMENT}

The main targets for JORDAN cloud government are improving the standard of living and reducing the communication gap with government agencies especially for a citizen who lives in rural or outside country. For developing countries as Jordan these targets can be achieved through adopting cloud technology especially in government agencies. This Adaptation ensures collaboration between government agencies. By ensuring infusion and diffusion of cloud government, Jordanian government will gain several benefits and valuable values and these benefits not limited to what is mentioned here [3, 6, 24-27]:

1- Cost -effective approach: one of the main challenges that faces Jordan cloud government even e- government is a shortage in budget. By implementing cloud paradigm, governmental agencies create a pool of shared and common resources as: software, hardware and network infrastructure even employee that leads to reduction in cloud-government budget. However, the budget is one of significant barriers that faced developing country, such as Jordan [24].

2- Agility: Cloud computing ensures the resources availability when they are needed by eliminating activities that consume time for resources allocation. So, citizens will have real time services.

3- Reduce administration overload: government has to administrate and maintain IT resources. This mission in converted to one of cloud service provider responsibilities. In addition, this will lead to reduce the needs for IT human resources and will allow the governmental agencies to spot their focus on the most significant working areas.
4- Green Technology: One of new trends in IT sector is reducing the negative impact of power consumption on air pollution. This target satisfied by using virtual services [26].

5- Disasters Recovery: keeping system available any time for citizen is a significant need for cloud government this need satisfied by recovering system after any disaster caused by IT infrastructure or attacks, so the backup copies can be kept using cloud resources to reduce time and storage capacities[25].

6- Mobility: Citizens and government employees be able to access to their information rather than staying at their desks.

7- Efficiency and effectiveness: By achieving more work with less time and resources [27].

8- New Business Models: it became easier to create and innovate new business model by taking advantages of existing cloud resources. The New business model will add a value for both citizens and government agencies. By creating new business models, new revenue models will take a place in the local economy.

9- Building Strong Relationships with clients. Different government agencies, as banks, have been used as a data center for client information and their processes where this feature will enable these agencies from developing better citizen's solutions and making better decision on behalf of them.

The following benefits can also be joined to the above list [17].

- Usability

- Quality of Service

- Managing Information Technology

- Value added facilities and easier maintenance Furthermore, there was a survey conducted in October and November 2010 on more than 15000 employees from variety sectors; government and private business enterprises about government product and services. Table 3 summarizes the cloud drivers that the survey respondents [18].

Table 3: Cloud Drivers [18]

\begin{tabular}{|c|c|}
\hline Drivers & $\begin{array}{c}\text { Percent of } \\
\text { Respondents }\end{array}$ \\
\hline Enable business continuity & 79 \\
\hline Greater flexibility & 77 \\
\hline Improve customer support or services & 76 \\
\hline Reduce resource waste & 75 \\
\hline Enable innovation & 70 \\
\hline Need for real-time information & 65 \\
\hline Gain a competitive edge & 65 \\
\hline Expand revenue opportunities & 63 \\
\hline Cost Reduction & 61 \\
\hline
\end{tabular}

\section{CHALLENGES IN IMPLEMENTING CLOUD GOVERNMENT}

Implementing cloud government has mission and vision aimed to accomplished. This vision concentrated on enable complete and secure e-government where the mission focus on developing and managing e-Government infrastructure 
with keeping on continuous research, development and specifying standard for applying e-government. In addition, egovernment has to support and train e-government staff.

For cloud government adaptation, several challenges have to be faced and some of these challenges are:

Security and privacy is one of the critical cloud government concerns. To satisfy security in cloud government, several Security requirements have to take a place which they are: "confidentiality, availability and integrity of data or information" [23]. Security plays an important role in establishing the trust of the citizens in cloud government. So, e-government can be considered as a cloud computing application and service which should meet the security level of cloud environment. The Network environment suffers from different attempts of attack that will volatile security requirement. Security attacks can be classified as Denial of Service (DoS) that makes system resources out of service and other attacks as Probe, U2R and U2L [19]. Also, citizen data is stored remotely and controlled by third part. In this situation, citizens concerned about their data privacy and authorized access [3, 6, 20, 21, 23, 28].

1- Reliability: ensure that operational infrastructure and related data are ready to be used and work properly even in catastrophic and in unexpected situations.

2- Managing Cloud: according to the changed needs of citizens, a cloud service provider is going to update and change services rapidly across organization units independently without involvement of government IT staff. So maintaining overall control and gaining ongoing updates is a difficult task of IT staff. In addition, cloud government staff must have the capabilities to monitor cloud service provider and internal services where these capabilities developed internally or outsourced.

3- Interoperability: In a cloud environment, different service provider can collaborate to provide comprehensive services. According to that, there is a need to guarantee the citizen's applications and data can be exchanged probably between cloud government service providers. For This purpose, they have to develop a uniform interface for cross functionality platform [28].

4- Regulation: There has to be a set of rules and governmental regulations that govern cloud government. These rules and regulations may differ between countries so there is a need to have standard regulation shared between different countries especially if there is collaboration between cloud governments.

For implementing Jordanian Cloud-government, several stages must be determined to gain wanted results and achieve high performance services for Jordanian citizens. But firstly there is a need to identify the deployment model for cloud environment where these models are: internal or private, cloud, public cloud, community cloud, and hybrid cloud [20, 21, 22]. As shown in figure 4.

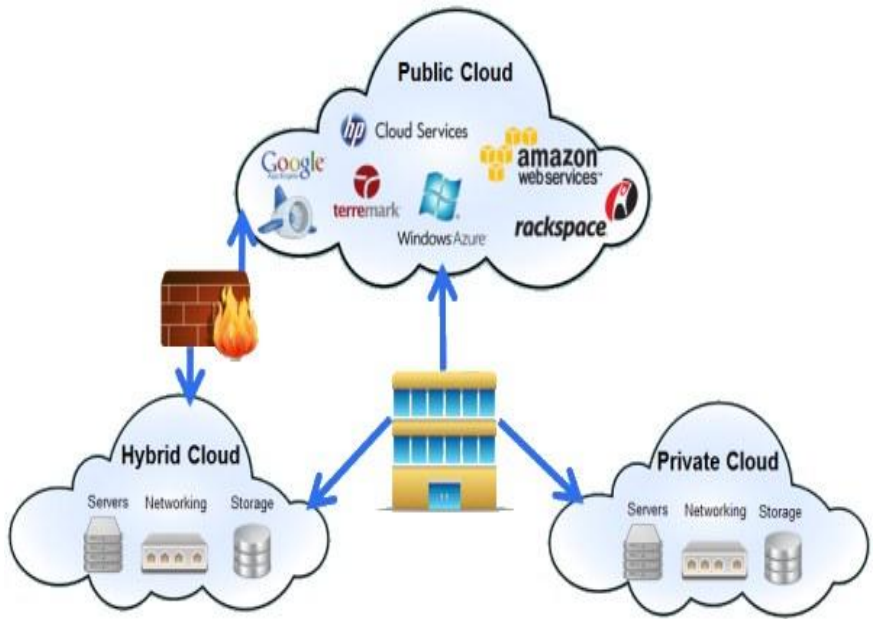

Fig. 4. Cloud Models [29]

Private Cloud: is functioned by specific organization either managed by itself or by third party as cloud provider[7, 20, 21, 22].

Public Cloud: government agency hold a contract with third party such as cloud service provider to present and sell public governmental services for citizens, also these governmental services managed only by this third party.

Hybrid Cloud: is structured from two or more clouds: public, private and community $[7,20,21,22]$. In addition, government agencies can outsource regular and low risks services and information and services, Public cloud, where high risk services and information remain under their control. $[7,20,21,22]$. As shown in figure 5 .

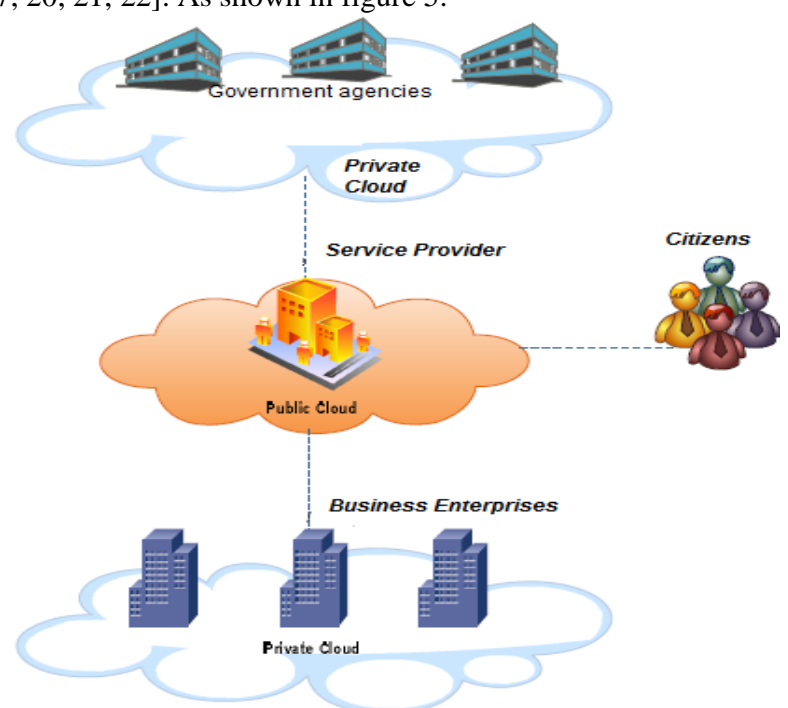

Fig. 5. Hybrid Cloud Model [29]

The main suggested stages that may be followed to transfer Jordanian e-government to be Cloud Government as shown in figure 6 , and these stages are summarized as follows: 


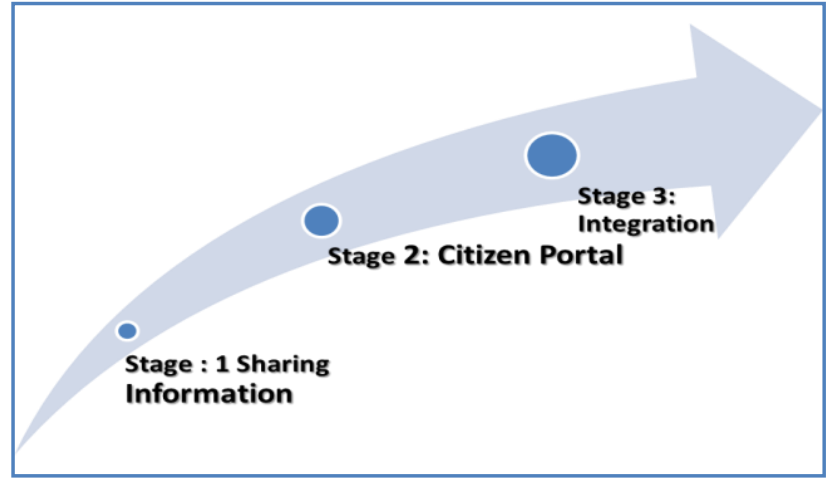

Fig. 6. Jordanian Cloud Government Road Map Stages 1: Information Publishing: this step involves planning to adapt cloud government through sharing knowledge between employees of government agencies and citizens. Also, explain the road map, rules, contract regulation of this adaptation.

Stages 2: Citizens Portal: government goes into a forward step from the theoretical into primarily strategic low cost services through government portal by using public clouds where infrastructure is shared between different government agencies.

Stages 3: Gradually Integration. Government agencies start with steady steps to integrate strategies, rules and policies with the cloud government backbones, Data Centers. This integration carried out by using public or community cloud deployment model. Hybrid model can take a place in this stage according to sensitivity of government agencies tasks and services.

\section{CONCLUSION}

From this paper, we can conclude that there are serious needs to lead developing countries, especially Jordan, to change their ways in order to provide services for their citizens as well as to reduce costs and sustain themselves in this changed environment. Cloud is the most appropriate way to accelerate adaptation of green and low-cost technology. Definitely, the participating government agencies and even countries with each other can guarantee the successful of cloud government. Gradual adaptation for cloud government will eliminate and minimize obstacles that will face cloud adaptation.

\section{REFERENCES}

[1] Turban,E., King,D. 2011. Electronic Commerce. Prentice Hall. 3rd Edition.

[2] http://unpan3.un.org/egovkb/en-us/Data/CountryInformation/id/86-Jordan/dataYear/2014.

[3] Soleimanian , F., Hashemi, S.2012. Security Challenges in Cloud Computing with More Emphasis on Trust and Privacy. International Journal of Scientific \& Technology Research, Vol. 1, ISSUE 6, pp. 49-54.

[4] Sasikala ,P.2012. Cloud Computing and E-Governance: Advances, Opportunities and Challenges. International Journal of Cloud Applications and Computing (IJCAC). Volume 2, Issue 4. 21 pages.

[5] Jensen, M., Schwenk,J., Gruschka,N., Iacon,L .2009. On technical Security Issues in Cloud Computing. Proc. of IEEE International Conference on Cloud Computing (CLOUD-II, 2009), pp. 109-116, India.

[6] Alshomrani,S.,Qamar,Sh. 2013. Cloud Based EGovernment: Benefits and Challenges, , International
Journal of Multidisciplinary Science and Engineering. Vol.4, No.6.

[7] Hashemi,S.,Monfaredi,Kh., Masdari,M.2013. Using Cloud Computing for E-Government: Challenges and Benefits. International Journal of Computer, Information, Systems and Control Engineering Vol.7 No.9.

[8] Bertot, J., Jaeger, P. 2006. User-centered e-government: Challenges and benefits for government Web sites. Government Information Quarterly,23(2),163-168.

[9] Venkatesh, V., Chan, F. K., Thong, J. Y. 2012. Designing e-government services: Key service attributes and citizens' preference structures. Journal of Operations Management, 30(1), 116-133.

[10] Affisco, J. F., \& Soliman, K. S. 2006. E-government: a strategic operations management framework for service delivery. Business Process Management Journal, 12(1), 13-21.

[11] Pan, S. L., Tan, C.W., \& Lim, E.T. 2006. Customer relationship management (CRM) in e-government: a relational perspective. Decision Support Systems, 42(1), 237-250.

[12] Ciborra, C. 2005. Interpreting e-government and development: Efficiency, transparency or governance at a distance?. Information Technology \& People,18(3), 260279 .

[13] Margetts,H.,\& Dunleavy,P.2002. Cultural barriers to egovernment. Academic article in support of better public services through e-government. National Audit Office, Ordered by the House of Commons, London.

[14] Rogers, E.M. 1995. Diffusion of Innovation. Free Press, New York.

[15] Dwivedi, Y. K., \& Williams, M. D. 2008. Demographic influence on UK citizens'-government adoption. Electronic Government, an International Journal, 5(3), 261-274

[16] Kim, T. H., Im, K. H., \& Park, S. C. 2005. Intelligent measuring and improving model for customer satisfaction level in e-government. In Electronic Government(pp. 38-48). Springer Berlin Heidelberg.

[17] Sosinsky, B. 2011. Cloud Computing Bible. Publisher: Wiley.

[18] Macias, F., Thomas,G. 2011. Cloud Computing Advantages in the Public Sector : How Today's Government, Education, and Healthcare. CISCO press.

[19] W.Alsharafat, W. 2014. Classifier System in cloud environment to Detect Denial of Service Attack, International Journal of Computer Applications.

[20] Soleimanian, F., Hashemi,S. 2012. Security Challenges in Cloud Computing with More Emphasis on Trust and Privacy, international journal of scientific \& technology research, 1(6), 49-54.

[21] Takabi,H., Joshi,J., Ahn,G. 2010. Security and Privacy Challenges in Cloud Computing Environments, IEEE Security Privacy Magazine, 8, pp24-3.

[22] Sosinsky, B. 2011. Cloud Computing Bible. Publisher: Wiley.

[23] Stalleing,W. 2008. Computer and network Security, 
Prentice Hall, 3rd Edition.

[24] Eric A., Lozano, B. 2010. Executive's Guide to Cloud Computing. Hoboken, New Jersey: John Wiley and Sons, PP. $40-102$.

[25] Buyya, R., Broberg,J., Goscinski, A. 2011. Cloud Computing: Principles and Paradigms. Hoboken, New Jersey: John Wiley and Sons.

[26] Tripathi, A., Parihar,B. 2011. E-governance challenges and cloud benefit. IEEE International Conference on Computer Science and Automation Engineering. Publisher: IEEE, pp.: 351-354.
[27] Macias, F., Thomas, G. 2011. Cloud Computing Advantages in Public Sector. Cisco Press. 1-7.

[28] Sutherland,S. 2013. Convergence of Interoperability of Cloud Computing, Service Oriented Architecture and Enterprise Architecture, International Journal of EEntrepreneurship and Innovation (IJEEI), Vol.4,No.1. 9 pages.

[29] https://images.search.yahoo.com/search/images_ylt=Awr B8pqkQGNWFjYAT_WJzbkF?p=cloud+computing

[30] N. Kho. 2009. Content in the cloud. EContent Mag 